\title{
A INTEGRAÇÃO DA CONVENÇÃO AMERICANA SOBRE DIREITOS HUMANOS NO BRASIL: A (IN)APLICABILIDADE DA TEORIA DO DUPLO CONTROLE
}

\author{
Alberto Hora Mendonça Filho ${ }^{1}$ \\ Clara Cardoso Machado Jaborandy ${ }^{2}$
}

RESUMO: Em decorrência da internacionalização das normas jurídicas, os tratados internacionais detêm relevante papel na proteção dos direitos humanos. Visto isso, importante estudar a fenomenologia jurídica da incorporação da Convenção Americana sobre Direitos Humanos ao ordenamento pátrio, sobretudo a (in)aplicabilidade da teoria do duplo controle. Utiliza-se, para tanto, uma pesquisa qualitativa, sendo bibliográfico-documental, já que foram consultados artigos científicos e obras jurídicas, como regras legais, convencionais e constitucionais. Adotou-se ainda o método dedutivo. Ao cabo, conclui-se pela necessidade de se ter a CADH como componente do bloco de constitucionalidade para uma adequada proteção aos direitos humanos.

Palavras-chave: CADH. Convencionalidade. Aplicabilidade. Jurisprudência. Guerrilha do Araguaia. Audiência de Custódia.

\section{THE INTEGRATION OF THE AMERICAN CONVENTION ON HUMAN RIGHTS IN BRAZIL: THE (IN) APPLICABILITY OF THE DOUBLE CONTROL THEORY}

\begin{abstract}
As a result of the internationalization of legal norms, international treaties play a relevant role in the protection of human rights. Therefore it is important to study the juridical phenomenology of incorporating the American Convention on Human Rights into the national order, especially the (in) applicability of the double control theory. For this purpose, it is used a qualitative research and a bibliographical-documentary, because scientific articles and books were consulted, as well as legal, conventional and constitutional rules. The method was the deductive. So it is necessary consider ACHR as part of the constitutionality block to protect the human rights.
\end{abstract}

\footnotetext{
${ }^{1}$ Advogado. Mestrando em Direitos Humanos pela Universidade Tiradentes (UNIT/SE). Bacharel em Direito pela UNIT/SE. Integrante do Grupo de Pesquisa "Novas tecnologias e o impacto nos Direitos Humanos", presente no diretório do CNPq. Endereço eletrônico: alberto-ah-30@hotmail.com.

${ }^{2}$ Doutora em Direito pela Universidade Federal da Bahia (UFBA). Mestre pela UFBA. Professora do Mestrado em Direitos Humanos da UNIT. Coordenadora do Grupo de pesquisa "Direitos Fundamentais, novos direitos e evolução social". Endereço eletrônico: claracardosomachado@gmail.com.
} 
Keywords: ACHR. Conventionality. Applicability. Jurisprudence. Araguaia Guerrilla. Hearing.

\section{INTRODUÇÃO}

Em virtude da robusta internacionalização das normas jurídicas, pode-se dizer que, na atualidade, não é apenas a Constituição que ocupa o pináculo da ordem jurídica doméstica, mas também as normas internacionais, que aderem ao direito constitucional pátrio, o que enseja, portanto, mais do que nunca, um diálogo jurisprudencial entre as Cortes e os demais atores do mundo do Direito de todos os poderes e variados Estados (FIGUEIREDO, p. 78-79).

O art. $5^{\circ}, \S 2^{\circ}$, da Constituição brasileira, por exemplo, é tido como uma cláusula aberta de recepção, de modo que outros diplomas internacionais, a exemplo da própria Convenção Americana sobre Direitos Humanos, podem acrescer direitos e garantias sem prejuízo àqueles previstos na carta política.

Assim, como a jurisprudência do Supremo Tribunal Federal é no sentido que essa convenção detém tão somente o status de supralegalidade, submetendo-se, portanto, à supremacia constitucional, aponta-se que a legislação ordinária é controlada duplamente, isto é, pela Carta Magna e pela Convenção.

Nesse contexto, é imperioso estudar a fenomenologia jurídica da incorporação da Convenção Americana sobre Direitos Humanos ao ordenamento pátrio, sobretudo no pertinente à (in)aplicabilidade da teoria do duplo controle.

Especificamente, busca-se verificar se há um retrocesso em direitos humanos em inferiorizar ou até mesmo negar o status hierárquico desse pacto ao se integralizar à ordem interna brasileira ou se consiste apenas numa questão peculiar da soberania nacional.

Utiliza-se, para tanto, uma pesquisa qualitativa, pois a intenção consiste em explorar o conjunto complexo de fatores que envolvem o fenômeno central (CRESWELL, 2010, p. 162). No que diz respeito à abordagem, trata-se ainda de pesquisa bibliográfico-documental, na medida em que se vale tanto de artigos científicos e obras jurídicas, como de normas infraconstitucionais, convencionais e constitucionais.

Em vista à necessária revisitação da literatura já produzida acerca da temática, far-seá um levantamento bibliográfico inicial, para que seja então conceituada a Teoria do Duplo 
Controle e como se dá a integração do Pacto de São José da Costa Rica nos ordenamentos latinos (MARCONI; LAKATOS, 2011).

Adota-se, então, o método dedutivo, haja vista que a partir da fenomenologia da incorporação da Convenção Americana sobre Direitos Humanos à ordem jurídica brasileira, buscam-se conclusões formais a partir de tal marco teórico (MEZZAROBA; MONTEIRO, 2009, p. 65).

Diante disso, apresenta-se, em um primeiro instante, como ocorre a integração da Convenção Americana sobre Direitos Humanos (CADH) na ordem jurídica brasileira. Em sequência, define-se a teoria do duplo controle e é explicada a sua adequação ao Direito pátrio. Após, esboça-se o panorama da efetividade da CADH no Brasil a partir do Caso Gomes Lund e outros vs. Brasil, da (a)tipicidade do crime de desacato e da (in)obrigatoriedade da audiência de custódia. Por fim, desenha-se uma análise crítica sobre o paroquialismo jurídico reticente ao cumprimento da CADH.

\section{DA INTEGRAÇÃO DA CONVENÇÃO AMERICANA SOBRE DIREITOS HUMANOS À ORDEM JURÍDICA BRASILEIRA}

A Constituição Federal (CF/88) indica, expressamente, no art. $5^{\circ}$, $\S 2^{\circ}$, que os direitos e garantias ali previstos "não excluem outros decorrentes do regime e dos princípios por ela adotados, ou dos tratados internacionais em que a República Federativa do Brasil seja parte” (BRASIL, 1988).

De igual modo, a Constituição da Nação Argentina (1994) revela, em seu art. 33, que os direitos e garantias nela prescritos não serão entendidos como negativa a outros ali não previstos.

Em razão disso, Piovesan (2016, p. 122) diz, com relação ao cenário brasileiro, que “a Carta de 1988 está a incluir, no catálogo de direitos constitucionalmente protegidos, os direitos enunciados nos tratados internacionais em que o Brasil seja parte”, o que se alinha, como visto, ao viés adotado por outros países.

Nesse contexto, o tratado é considerado a principal fonte do Direito Internacional, sendo conceituado como "um acordo internacional concluído por escrito entre Estados ou entre Estados e Organizações Internacionais, regido pelo Direito Internacional”, seja por meio de um 
instrumento único, seja por dois ou mais instrumentos conexos, independentemente de sua denominação específica (VARELLA, p. 37).

Atento a isso é que Ramos (2016, p. 424) define o bloco de constitucionalidade como “o reconhecimento da existência de outros diplomas normativos de hierarquia constitucional, além da própria Constituição".

Segundo Melo e Bonato (2017, p. 302), a inclusão dos tratados internacionais na cláusula de abertura dos direitos fundamentais oriunda uma nova perspectiva para o Direito Constitucional, traduzindo uma cooperatividade, visto que resulta num compromisso formal da constituição em assegurar a proteção aos direitos humanos.

Muito em consonância à prevalência dos direitos humanos que deve reger as relações internacionais da República brasileira, de acordo com o art. 4º II, da CF/88, a Emenda Constitucional $n^{\circ} 45$, de 30 de dezembro de 2004, acrescentou então o art. $5^{\circ}$, $\S 3^{\circ}$, da Carta Magna, criando um rito formal, segundo o qual os tratados e convenções internacionais, que versem sobre direitos humanos e "forem aprovados, em cada Casa do Congresso Nacional, em dois turnos, por três quintos dos votos dos respectivos membros, serão equivalentes às emendas constitucionais” (BRASIL, 1988).

A despeito disso, restou ainda uma grave lacuna quanto àqueles tratados sobre direitos humanos que não se sujeitaram a esse rito, o que ocasionou um retumbante debate quanto a posição hierárquica desses tratados na ordem interna brasileira.

Convém lembrar que o "primado da constituição, em confronto com a norma pacta sunt servanda, é corrente que se preserve a autoridade da lei fundamental do Estado, ainda que isto signifique a prática de um ilícito pelo qual, no plano externo, deve aquele responder” (REZEK, 2016, p. 128), a controvérsia, então, como mencionado acima, é sobre a antinomia entre os diplomas internacionais e a legislação infraconstitucional.

A título de exemplo, de modo diverso ao silêncio constitucional adotado pelo constituinte brasileiro, quanto ao status normativo dos tratados sobre direitos humanos (não submetidos ao rito formal específico), a Constituição argentina, em seu art. 75, inciso 22, expressamente, menciona que “los tratados y concordatos tienen jerarquía superior a las leyes” (ARGENTINA, 1994). 
3 A TEORIA DO DUPLO CONTROLE: CONCEITO E ADEQUAÇÃO AO DIREITO PÁTRIO

A partir desse panorama, entende-se que vigora um novo tipo de controle da produção legiferante doméstica, qual seja, o controle de convencionalidade das leis. Isso porque os tratados de direitos humanos podem ser materialmente constitucionais, aqueles previstos no art. $5^{\circ}$, § $2^{\circ}$, da CF/88, ou material e formalmente constitucional, quando se coadunam ao parágrafo terceiro do citado dispositivo (MAZZUOLI, 2009, p.114).

Em outros termos, há, portanto, controle de convencionalidade para os tratados sobre direitos humanos materialmente constitucionais e de constitucionalidade para os que foram sufragados por meio do citado rito.

Por isso, Lopes Jr. (2017a, p. 33) exemplifica que o processo penal requer mais do que mera legalidade e sim uma afinidade às regras constitucionais do jogo (devido processo) na dimensão formal, mas, sobretudo, substancial, isto é, que resista à filtragem constitucional e convencional - Convenção Americana de Direitos Humanas, CADH.

Esse cenário alinha então dois critérios, a saber, o diálogo das cortes, de natureza preventiva, em que os tribunais domésticos e internacionais devem se coadunar à proteção internacional dos direitos humanos e a teoria do duplo controle, segundo a qual "os direitos humanos possuem no Brasil uma dupla garantia: controle abstrato de constitucionalidade, exercido pelo Supremo Tribunal Federal, e o controle de convencionalidade autêntico, exercido pela Corte Interamericana de Direitos Humanos” (PAIVA; HEEMAN, 2015, p. 242).

Em 25 de novembro de 2003, a Corte Interamericana de Direitos Humanos utilizou pela primeira vez esse mecanismo no julgamento Myrna Marc Chang vs. Guatemala, oportunidade em que o juiz Sergio Garcia Ramirez destacou:

Para los efectos de la Convención Americana y del ejercicio de la jurisdicción contenciosa de la Corte Interamericana, el Estado viene a cuentas en forma integral, como un todo. En este orden, la responsabilidad es global, atañe al Estado en su conjunto y no puede quedar sujeta a la división de atribuciones que señale el Derecho interno. No es posible seccionar internacionalmente al Estado, obligar ante la Corte sólo a uno o algunos de sus órganos, entregar a éstos la representación del Estado en 
el juicio --sin que esa representación repercuta sobre el Estado en su conjunto-- y sustraer a otros de este régimen convencional de responsabilidad, dejando sus actuaciones fuera del “control de convencionalidad” que trae consigo la jurisdicción de la Corte internacional (CIDH, 2003, p. 165).

De tal modo, pode-se dizer que o controle de convencionalidade reside na análise da (in)compatibilidade dos atos internos, comissivos ou omissivos, "em face das normas internacionais (tratados, costumes internacionais, princípios gerais de direito, atos unilaterais, resoluções vinculantes de organizações internacionais)”. Resulta então num efeito negativo ou positivo, isto significa, respectivamente, a invalidação das normas e decisões nacionais contrárias às normas internacionais (denomina-se: controle destrutivo ou saneador de convencionalidade) ou na interpretação adequada das normas nacionais em conformidade às internacionais, conhecido como controle construtivo de convencionalidade (RAMOS, 2016, p. 427).

Em idêntico sentido, o Supremo Tribunal Federal (STF), em sede de Recurso Extraordinário, registrado sob o $n^{\circ} 466343$, atribuiu o status de supralegalidade aos tratados que versam sobre direitos humanos, mas que não enfrentaram o já citado rito constitucional, como é o caso da Convenção Americana de Direitos Humanos. Isso porque “os tratados sobre direitos humanos não poderiam afrontar a supremacia da Constituição, mas teriam lugar especial reservado no ordenamento jurídico. Equipará-los à legislação ordinária seria subestimar o seu valor especial no contexto do sistema de proteção dos direitos da pessoa humana” (BRASIL, 2009).

No entanto, situações de desrespeito à Convenção Americana sobre Direitos Humanos e à própria decisão da Corte, como demonstrado posteriormente, revelam a necessidade de um estudo crítico sobre a (in)suficiência da supralegalidade na proteção aos direitos humanos.

4 ALGUNS CASOS EXEMPLIFICATIVOS DA (IN)EFETIVIDADE DA CONVENÇÃO E DAS DECISÕES DA CORTE NO BRASIL 
4.1 A Guerrilha do Araguaia: a Lei de Anistia como uma inconveniente constitucionalidade

Talvez o mais emblemático caso brasileiro sobre a aplicabilidade da Convenção Americana sobre Direitos Humanos seja o episódio que veio a ser denominado de "A Guerrilha do Araguaia”3.

Influenciados pelos pressupostos teóricos chineses, segundo os quais um amplo processo de mobilização popular campesino (“trabalho de massas”), de modo que a guerrilha seria tão somente uma etapa, conforme demonstra o documento "Guerra popular: caminho da luta armada no Brasil” (PARTIDO COMUNISTA DO BRASIL, 2010), os militantes do PCdoB, em meados da década de 60, implementaram a guerrilha na remota região do "Bico do Papagaio”, que engloba territórios do sudeste do Pará, norte do estado de Goiás, à época (hoje, Tocantins), e também terras maranhenses (PEIXOTO, 2011).

Esse movimento encontrou seu termo em 1974, momento em que os últimos combatentes foram caçados e abatidos pelos militares. A demora, muito em virtude do fator geográfico, evidencia a robusta dificuldade da Repressão em derrotar os revolucionários, como mesmo conta Carlos Alberto de Fontoura, chefe, à época, do Serviço Nacional de Informações - SNI:

\begin{abstract}
As Forças Armadas, como a Polícia, não tinham preparo para combater a guerra de guerrilha. Nenhum. Eu não tenho qualquer escrúpulo em dizer isso: as Forças Armadas não estavam preparadas para aquele combate. Tanto que levou muito tempo para acabar. Começou em 65, 66, 67, mas a guerrilha do Araguaia só foi acabar no governo do Geisel. Vejam o tempo que levou. O filho de um amigo meu, o general Enio Pinheiro, levou um tiro na boca na guerrilha do Araguaia. Entrou no mato, na floresta amazônica, o guerrilheiro estava escondido e deu um tiro nele. Quer dizer, era uma coisa tremenda (D’ARAUJO, SOARES, CASTRO, p. 84-85).
\end{abstract}

Dentre os militantes, havia Guilherme Gomes Lund, estudante da Faculdade Nacional de Arquitetura da Universidade Federal do Rio de Janeiro (UFRJ), cujo nome figura no famoso caso decidido pela Corte Interamericana de Direitos Humanos e que faleceu em dezembro de 1973, sendo que seus familiares apenas souberam da sua adesão à guerrilha em 1979, por intermédio do Comitê Brasileiro pela Anistia (BRASIL, 2014, p. 1490).

\footnotetext{
${ }^{3}$ Segundo Nunes, Jacob e Gomes (2016, p. 217), não há que se falar, conceitualmente, em “guerrilha”, porque o que aconteceu, de fato, foi um massacre na busca, captura e extermínio dos ditos terroristas escondidos na mata.
} 
As perseguições políticas e prisões arbitrárias eram a tônica do Regime Militar na repressão aos esquerdistas, mas também àqueles que destoavam do sistema, como é visível na cassação dos direitos políticos de Juscelino Kubitschek e até mesmo de ministros do Supremo Tribunal Federal, como é o caso de Evandro Lins e Silva e Hermes Lima (FERREIRA; GOMES, 2014, p. 386).

Com a redemocratização, animou-se o anseio popular pela identificação e responsabilização jurídica dos agentes da Repressão, tanto o é que houve a criação dos Comitês Brasileiros pela Anistia (CBAs) em 1978, o que reforçou a campanha pela anistia ampla, geral e irrestrita (TELES, 2010, p. 71-72).

Esse anseio é visível em reproduções culturais da época, como é o exemplo da composição Apesar de Você (1970) do cantor Chico Buarque de Holanda, na qual há, logo no próprio, a cisão entre o “eu” lírico, que representa todos os oprimidos, e o “você”, isto é, o despotismo estatal. Nesse contexto, acredita que, em dado instante (o amanhã), cobrará, com juros, todo o sofrimento resultante dos variados pecados da Ditadura:

\begin{abstract}
Hoje você é quem manda / Falou, tá falado / Não tem discussão, não / A minha gente hoje anda / Falando de lado / E olhando pro chão, viu [...] Quando chegar o momento / Esse meu sofrimento / Vou cobrar com juros, juro / Todo esse amor reprimido / Esse grito contido / Este samba no escuro / Você que inventou a tristeza / Ora, tenha a fineza / De desinventar / Você vai pagar e é dobrado / Cada lágrima rolada / Nesse meu penar [...] Apesar de você / Amanhã há de ser / Outro dia (HOLANDA, 1970).
\end{abstract}

Em que pese o prévio intuito de rejeitar a concessão de anistia aos torturadores ${ }^{4}$, o general João Batista Figueiredo sancionou, em 28 de agosto de 1979, a Lei n. 6.683, conhecida como “Lei de Anistia”, que prescreve:

Art. $1^{\circ}$ É concedida anistia a todos quantos, no período compreendido entre 02 de
setembro de 1961 e 15 de agosto de 1979 , cometeram crimes políticos ou conexo com
estes, crimes eleitorais, aos que tiveram seus direitos políticos suspensos e aos
servidores da Administração Direta e Indireta, de fundações vinculadas ao poder
público, aos Servidores dos Poderes Legislativo e Judiciário, aos Militares e aos
dirigentes e representantes sindicais, punidos com fundamento em Atos Institucionais
e Complementares. ${ }^{4}$ Tanto o MDB quanto os CBAs elaboraram emenda ao projeto de lei de anistia da base governista, pautado, em
síntese, nos seguintes aspectos: “rejeição da reciprocidade na concessão da anistia (art.1 $\left.{ }^{\circ}, \S 2^{\circ}\right)$, propunha a anistia
aos perseguidos políticos; a instauração de inquérito para apurar as circunstâncias dos desaparecimentos políticos,
(art.15), mas propunha a concessão de declaração de morte presumida para os desaparecidos políticos (art.16),
sem investigação prévia, similar à declaração de ausência do substitutivo da ARENA” (TELES, 2010, p. 72-73).
Todavia, a maioria governista no Congresso, as inflexíveis normas regimentais e o confuso rito de votação
culminaram na rejeição a este substitutivo, como destaca, pormenorizadamente, Teles (2010, p. 74-75). 
$\S 1^{\circ}$ - Consideram-se conexos, para efeito deste artigo, os crimes de qualquer natureza relacionados com crimes políticos ou praticados por motivação política.

$\S 2^{\circ}$ - Excetuam-se dos benefícios da anistia os que foram condenados pela prática de crimes de terrorismo, assalto, sequestro e atentado pessoal (BRASIL, 1979, grifo nosso).

Esse dispositivo de lei foi objeto da Arguição de Descumprimento de Preceito Fundamental (ADPF 153/DF), proposta pelo Conselho Federal da Ordem dos Advogados do Brasil, com o intuito de ser declarada a sua não recepção pela CF/88.

O STF julgou então, por maioria, improcedente a ação, apontando, dentre outros fundamentos, que, no Estado Democrático de Direito, o Judiciário não é competente para alterar ou redigir o enunciado normativo, o que lhe é cabível é a produção de normas distintas a partir dele, sendo vedada a revisão do acordo político como a lei de anistia (BRASIL, 2010, p. 54).

Porque, de acordo com o Ministro relator Eros Grau, fazia-se necessária, casuisticamente, a interpretação o seu texto conforme a realidade no e do momento histórico de sua criação, desvencilhando-se da atualidade. De tal modo, a Lei 6.683/79 vinculou verdadeira escolha política no momento de transição para o regime democrático (BRASIL, 2010, p. 45).

Para Barrientos-Parra e Mialhe (2012, p. 39), o STF perdeu uma histórica chance no sentido de permitir o julgamento e eventual penalização dos agentes estatais amparados pela Lei de Anistia (Lei 6.683/79). Como resultado disso, todos aqueles que cometeram delitos comuns conexos aos políticos continuaram, criminalmente, impunes.

Acontece que, em 26 de março de 2009, a Comissão Interamericana de Direitos Humanos (CIDH) submeteu à Corte uma demanda em desfavor da República Federativa do Brasil em razão de petição apresentada, em 7 de agosto de 1995, pelo Centro pela Justiça e o Direito Internacional (CEJIL) e pela Human Rights Watch/Americas, em nome das pessoas desaparecidas no contexto da Guerrilha do Araguaia e seus familiares (CIDH, 2010, p. 03).

O objeto da demanda consistia na responsabilização do Estado brasileiro pela violação de inúmeros direitos, tais como a vida, reconhecimento da personalidade jurídica, integridade pessoal, liberdade, garantias judiciais, liberdade de pensamento, de expressão e proteção judicial, além da pretensão de que o demandado adotasse medidas de reparação (CIDH, 2010, p. 04).

Ao termo, a Corte (2010, p. 113) julgou, por unanimidade, a inconvecionalidade das disposições previstas na Lei de Anistia (Lei n. 6.683/79), haja vista que impediam a investigação e punição de severas violações de direitos humanos, na medida em que essa lei 
não pode configurar óbice à investigação dos fatos e, por conseguinte, individualização e punição dos responsáveis, sendo, portanto, ineficaz.

A título de registro, vale lembrar que o Estado brasileiro alegou, preliminarmente, dentre outros pontos, o esgotamento regular dos recursos internos, o que despertaria, inclusive, um obstáculo para o exame do mérito da questão, uma vez que é vedado uma quarta instância. Afinal, incumbe aos órgãos do Sistema Interamericano a atuação subsidiária, de modo que não podem ser tidos como tribunais de alçada, que operacionalizariam reexame fático-jurídico da matéria decidas, internamente, pelos tribunais.

A motivação da Corte (2010, p. 20), para afastá-la, centrava-se no fato de que o objeto da ADPF consistia em "evitar ou reparar uma possível lesão a uma norma fundamental, que, no caso perante o Supremo Tribunal Federal, se expressava em uma determinada interpretação constitucional”, sendo inadequada para reparar as violações alegadas a partir da averiguação dos fatos, a individualização das condutas e, enfim, a responsabilização jurídica e determinação do paradeiro dos desaparecidos.

4.2 A (ou a)tipicidade do crime de Desacato: o vai e vem da jurisprudência do Superior Tribunal de Justiça

O Código Penal brasileiro (1940) tipifica, no art. 331, a conduta de “desacatar funcionário público no exercício da função ou em razão dela”, à qual comina a pena de detenção de seis meses a dois anos ou multa.

No Recurso Especial n ${ }^{\circ}$ 1.640.084/SP, a quinta turma do Superior Tribunal de Justiça, em 15 de dezembro de 2016, decidiu pelo afastamento da tipificação criminal do desacato, na medida em que, reconhecendo que as normas da Convenção detêm o condão de destituir a validade de leis ordinárias antagônicas, a criminalização do desacato estaria "na contramão do humanismo, porque ressalta a preponderância do Estado - personificado em seus agentes sobre o indivíduo” (BRASIL, 2016).

Em específico, a Convenção (1969) ampara o direito à liberdade de pensamento e de expressão, ao passo em que determina no art. 13, 3, que: 
Não se pode restringir o direito de expressão por vias e meios indiretos, tais como o abuso de controles oficiais ou particulares de papel de imprensa, de frequências radioelétricas ou de equipamentos e aparelhos usados na difusão de informação, nem por quaisquer outros meios destinados a obstar a comunicação e a circulação de ideias e opiniões.

Todavia, por ocasião do julgamento do habeas corpus $n^{\circ}$ 379.269/MS, a terceira seção do Superior Tribunal de Justiça reputa como inexistente o conflito entre a figura penal do desacato e a convenção, além de ressaltar que, mesmo se houvesse decisão da Corte em sentido contrário, “[...] por si só, não seria suficiente a elidir a deliberação do Brasil acerca da aplicação de eventual julgado no seu âmbito doméstico, tudo isso por força da soberania que é inerente ao Estado” (2016, p. 3).

Nesse cenário, o Conselho Federal da Ordem dos Advogados do Brasil propôs a ADPF $496^{5}$ acerca da matéria em 30 de outubro de 2017, sendo da relatoria do Min. Luís Roberto Barroso e ainda aguarda julgamento pelo Plenário.

Há pouca esperança de declaração da atipicidade do crime de desacato, posto que, no Habeas Corpus $n^{\circ} 41949$, o STF entendeu que inexistiria qualquer tipo de incompatibilidade convencional.

4.3 A obrigatoriedade da Audiência de Custódia: um imperativo convencional.

A Convenção Americana sobre Direitos Humanos (1969), ao assegurar o direito à liberdade pessoal, garante, em seu art. $7^{\circ}, 5$, que “toda pessoa presa, detida ou retida deve ser conduzida, sem demora, à presença de um juiz ou outra autoridade autorizada por lei a exercer funções judiciais”, bem como detém “o direito de ser julgada em prazo razoável ou de ser posta em liberdade, sem prejuízo de que prossiga o processo”.

\footnotetext{
${ }^{5}$ O pedido consiste no reconhecimento da não recepção do artigo 331 do Código Penal pela Constituição Federal/1988, com o intuito "de se preservar os preceitos fundamentais da liberdade de expressão (art. $5^{\circ}$, incs. IX e 220, da CF), republicano (art. $1^{\circ}$, parágrafo único), da legalidade (art. $5^{\circ}$, inc. XXXIX), da igualdade (art. $5^{\circ}$, caput, da CF) e do Estado Democrático de Direito (art. $1^{\circ}$, da CF)”. Disponível em: $<$ https://www.conjur.com.br/dl/adpf-496-oab-desacato.pdf $>$.
} 
Diante disso, o Conselho Nacional de Justiça editou, em 15/12/2015, a Resolução no $213^{6}$ que “dispõe sobre a apresentação de toda pessoa presa à autoridade judicial no prazo de 24 horas":

\begin{abstract}
Art. $1^{\circ}$ Determinar que toda pessoa presa em flagrante delito, independentemente da motivação ou natureza do ato, seja obrigatoriamente apresentada, em até 24 horas da comunicação do flagrante, à autoridade judicial competente, e ouvida sobre as circunstâncias em que se realizou sua prisão ou apreensão (BRASIL, 2015).
\end{abstract}

Lopes Jr. (2017b, p. 75) defende que “a audiência de custódia humaniza o ato da prisão, permite o controle da legalidade do flagrante e, principalmente, cria condições melhores para o juiz avaliar a situação e a necessidade ou não da prisão cautelar”.

A despeito disso, o Superior Tribunal de Justiça (2016) sustenta o entendimento pelo qual a ausência de audiência de custódia per si é inapta a tornar ilegal a prisão cautelar, além de que a conversão do flagrante em preventiva a convalesceria, consoante Habeas Corpus (HC) n 3 344.989/RJ, 345.069/SP, Agravo Regimental no HC n³ 353.887/SP e Recurso Ordinário em $\mathrm{HC} \mathrm{n}^{\circ} 76.906 / \mathrm{SP}$.

Vale registrar que o STF, em sede de Habeas Corpus 133992, decidiu pela observância obrigatória da audiência de apresentação, como consectária lógica da Convenção Interamericana de Direitos Humanos, Pacto dos Direitos Civis e Políticos e do devido processo legal. Ademais, a conversão da prisão em flagrante em preventiva não redunda, por si só, a superação da irregularidade.

\footnotetext{
${ }^{6}$ Convém registrar o interessante argumento levantado pela Associação Nacional dos Magistrados Estaduais (Anamage), em sede de Ação Direita de Inconstitucionalidade, segundo o qual "o CNJ, ao editar a resolução, usurpou competência privativa do Congresso Nacional para legislar sobre matéria processual penal, em confronto com o inciso I do artigo 22 da Constituição Federal” (BRASIL 2016). Afinal, “a referida resolução tem o condão de interferir diretamente na atuação dos magistrados durante a condução das audiências de custódia", pois obriga a sua realização e detalha o papel do magistrado durante o ato, oferecendo-lhe protocolos e orientação sobre o modo de atuação. Entretanto, o Supremo Tribunal Federal negou seguimento a ação por ilegitimidade passiva. Veja-se, ainda, que, em nenhum momento, questiona-se a (in)obrigatoriedade da audiência, que constitui garantia convencional. Mais em: <http://www.stf.jus.br/portal/cms/verNoticiaDetalhe.asp?idConteudo=307642> e $<$ http://www.stf.jus.br/portal/cms/verNoticiaDetalhe.asp?idConteudo=309427>.
} 
5 O SISTEMA INTERAMERICANO DE PROTEÇÃO AOS DIREITOS HUMANOS: UMA CRÍTICA AO PAROQUIALISMO JURÍDICO

Sabe-se que a concepção contemporânea de direitos humanos atrela-se à “internacionalização dos direitos humanos, que constitui um movimento extremamente recente da história, surgindo, a partir do Pós-Guerra, como resposta às atrocidades e aos horrores cometidos durante o nazismo” (PIOVESAN, 2017, p. 50/51).

Por isso é, como registra Pagliarini (2012, p. 27-28), que “[...] não é necessário que o Direito Internacional seja incorporado pelo Direito interno (transformado em Direito nacional) de um país para se fazer valer”, nada obstante a existência de técnicas de recepção das normas internacionais, embora inaptas a eclipsar a existência do Direito Internacional (semelhante, inclusive, à do Direito Constitucional, qual seja, a estruturação de comunidades políticas e a declaração de direitos humanos, divergindo tão somente à respeito de quem os positiva).

Como visto, nos três episódios brasileiros descritos há desvelada antipatia à aplicação da Convenção Americana sobre Direitos Humanos, o que demonstra um paroquialismo jurídico refratário aos "mais nobres avanços que podem emergir de um esforço combinado e unido de todos os povos e nações” (OAB, 2009, p. 105).

Além de totalmente avesso ao propósito presente quando pactuada: “o conceber o Pacto de São José de Costa Rica, os Estados signatários reafirmam o propósito de consolidar no continente americano um regime de liberdade pessoal e de justiça social fundado no respeito aos direitos humanos essenciais” (GUERRA, 2015, p. 193).

Nesse contexto, é preciso ecoar o alerta de Martínez et al. (2008, p. 39), pelo qual a universalidade "es una de las características de los derechos humanos que com mayor facilidade puede caer em la abstracción, em uma mistificación semejante a lo que sucede con el bien común y, por tantom em la ya tan reiterada idelogización”.

Sobretudo, num momento em que se nota, cada vez mais visivelmente, um hiato entre o normatizado e a realidade das praxes institucionais, tampouco com o que anseia o clamor popular, que brada pela supressão de direitos e garantias (SILVEIRA; SCHNEISKI, 2017, p. 152-153). 
É possível avistar, com base nas ilusões e tensões quanto aos e dos direitos humanos, trazidas por Boaventura de Sousa Santos, uma razão comum para a (in)efetividade da CADH, sendo duas tensões específica aos caso Gomes Lund. e outro vs. Brasil.

Sousa (2013, p. 49-50) aponta que a finalidade de adotar tratados, declarações, instituições e regimes internacionais de direitos humanos objetiva a assegurar parcelas mínimas de “dignidade aos indivíduos sempre e quando os direitos de pertença a uma coletividade política não existissem ou fossem violados”. Como resultado dessa inferiorização dos direitos humanos "os direitos humanos surgem como o patamar mais baixo de inclusão, um movimento descendente da comunidade mais densa de cidadãos para a comunidade mais diluída da humanidade”.

Daí, nega-se o status constitucional de tratados e convenções sobre direitos humanos que não se submeterão ao rito formal do art. $5^{\circ}$, § $3^{\circ}$, da CF/88, ainda que não existente à época, como é o caso da CADH, tendo em vista que esse surgiu com a Emenda 45 de 2004, enquanto que o Brasil aderiu àquela em 6 de novembro de 1992 por meio do Decreto n. 678.

Além do mais, mesmo que tidas como normas supralegais, ou seja, como já explicitado, acima das leis ordinárias, não são de observância obrigatória, como decidiu, reiteradamente, o Superior Tribunal de Justiça a respeito da audiência de custódia.

Especificamente, sobre o caso da guerrilha do Araguaia, duas tensões somam-se ao monolitismo: a) o humano e o não humano; b) razão de Estado e razão dos direitos. Nesse viés, os militantes, por ostentarem uma ideologia política antitética ao Estado de Exceção, podem ser catalogados como sub-humanos, estando no lado de lá da linha abissal entre os plenamente humanos e os deficitários de humanidade (SANTOS, 2013, p. 76).

De outra banda, a segunda tensão ocorre entre “a continuidade dos direitos humanos e a descontinuidades dos regimes políticos”, na qual opera o domínio da justiça transicional ${ }^{7}$. No Brasil, defende-se, como o faz o próprio Supremo, a ideia de anistia como esquecimento e

\footnotetext{
${ }^{7}$ Acerca da Justiça de Transição, Silveira e Schneiski (2017, p. 156) esclarecem que, na condição de ramo interdisciplinar do Direito Internacional Humanitário, se trata de "verdadeiro espaço de diálogo, compreensão e memória dos que foram atingidos pelos abusos e pelo estado de não-direito nos regimes autoritários, através de processos de reconstrução histórica" com o objetivo de constatar as "falhas jurídicas e sociais nos sistemas de proteção da pessoa humana e a construção de ordem democrática pautada no mútuo respeito e na promoção dos direitos humanos".
} 


\section{A INTEGRAÇÃO DA CONVENÇÃO AMERICANA SOBRE DIREITOS HUMANOS NO BRASIL: A (IN)APLICABILIDADE DA TEORIA DO DUPLO CONTROLE}

conciliação, quando Estado deve pedir perdão e não se autoperdoar (SANTOS, 2013, p. 7173).

Nesse diapasão, importante registrar o papel desempenhado pela Comissão da Verdade $^{8}$, órgão temporário criado pela Lei 12.528, de 18 de novembro de 2011, que encerrou, com a entrega do seu Relatório Final, suas atividades em 10 de dezembro de 2014, e por todas as Comissões Estaduais da Verdade, às quais lembramos pela de Sergipe, criada, em 07 (sete) de julho de 2015, mediante o Decreto no 30030/2015.

Quanto a desacato, vale lembrar a distinção, trazida por Lafer (1988, p. 206), entre autoridade e poder, segundo a qual este requer, indiscutível e obrigatoriamente, de legitimidade popular, ao passo em que a primeira é o começo da ação conjunta e o legitima.

O sujeito passivo do crime de desacato é Administração Pública, isto é, a autoridade estatal. Entretanto, cuida-se de um tipo penal que restringe a liberdade de expressão do particular, própria do regime democrático, e sobrepõe a autoridade estatal personificada.

De modo nenhum, pretende-se que sejam autorizados impropérios atentados à honra do funcionário público no exercício de suas funções (a prol da sociedade), mas, como registrado pelo Min. Rel. Ribeiro Dantas (BRASIL, 2016), no Recurso Especial $n^{\circ} 1.640 .084 / S P$, há a proteção desse bem jurídicos por outros crimes, como a injúria, calúnia e a difamação, inclusive majorados pelo art. 141, II, do Código Penal.

\section{CONCLUSÃO}

Com base no exposto e considerando que o art. $5^{\circ}$, § $2^{\circ}$, da CF/88 é uma cláusula aberta de recepção, o bloco de constitucionalidade abarca os direitos e garantias fundamentais lá previstos, mas também aqueles postos em tratados e convenções internacionais dos quais o Brasil é signatário.

\footnotetext{
${ }^{8}$ Lafer (2013, p. 868) indica que as comissões da verdade "têm basicamente como objetivo estabelecer uma verdade sobre graves violações de direitos humanos ocorridas na vigência de regimes autoritários”, a sua concepção, portanto, é a de "instância $a d$ hoc da democratização da sociedade por um prazo determinado, com é o caso da brasileira (dois anos)".
} 
Nesse viés, a concepção contemporânea de direitos humanos, no entanto, vincula-se à internacionalização deles, como resposta aos horrores do nazifascismo. Por isso, pode-se dizer que é desnecessário um rito específico de recepção das normas internacionais, porquanto estas também declaram direitos humanos.

Ocorre que, com a criação do rito formal (art. 5º $\S 3^{\circ}$, CF/88) pela Emenda $n^{\circ} 45 / 04$, parcela considerável dos autores entende, com a chancela do STF, que os instrumentos de Direito Internacional, como a CADH, detêm o caráter de supralegalidade, o que ocasionaria a necessidade de um duplo controle das legislações ordinárias - ainda que integralizada ao direito brasileiro antes dessa reforma constitucional.

De qualquer sorte, verifica-se, a partir da ilustração de três casos brasileiros (quais sejam, o Caso Gomes Lund e outros vs. Brasil, a (in)observância da Audiência de Custódia e a (a)tipicidade do delito de desacato), a inaplicação da Convenção Americana sobre Direitos Humanos e a inércia quanto ao cumprimento da decisão da Corte pela jurisprudência pátria, o que remonta a um paroquialismo jurídico.

É preciso remontar que o universalismo é um dos caracteres dos direitos humanos que, mais facilmente, pode se tornar abstrato, razão pela qual a luta é de suma importância para fazer valer os direitos, porque a Convenção é um marco na luta pela união do continente americano, mas que é obstaculizado pelo monolitismo, na expressão de Santos. 


\section{REFERÊNCIAS}

ARgENTINA. Constitucion de la Nacion Argentina. 22 ago. 1994. Disponível em: <http://www.oas.org/juridico/mla/sp/arg/sp_arg-int-text-const.html>. Acesso em: 15 mar. 2018.

BARRIENTOS-PARRA, J.; MIALHE, J. L. Lei de Anistia: comentários à sentença do Supremo Tribunal Federal no caso da ADPF 153. Revista de informação legislativa, Brasília, v. 49, n. 194, p. 23-40, abr./jun. 2012. Disponível em: < http://www2.senado.leg.br/bdsf/handle/id/496575>. Acesso em: 29 mar. 2018.

BRASIL. Arguição De Descumprimento de Preceito Fundamental 153 Distrito Federal. Tribunal Pleno. Rel. Min. Eros Grau. Data de Julgamento: 29/04/2010. Data de Publicação: 06/08/2010.

Comissão Nacional da Verdade. Mortos e desaparecidos políticos / Comissão Nacional da Verdade. - Brasília: CNV, 2014.

Constituição (1988). Constituição da República Federativa do Brasil. Diário Oficial [da] República Federativa do Brasil, Brasília, DF, 5 out. 1988. Disponível em: <http://www.planalto.gov.br/ccivil_03/constituicao/constituicao.htm>. Acesso em: 15 mar. 2018.

Código Penal. Decreto-Lei $\mathrm{n}^{\circ}$ 2.848, 7 de dezembro de 1940. Disponível em: <http://www.planalto.gov.br/ccivil_03/decreto-lei/Del2848compilado.htm>. Acesso em: 30 mar. 2018.

Lei n. 6.683, 28 de agosto de 1979. Concede anistia e dá outras providências. Disponível em: http://www.planalto.gov.br/ccivil_03/leis/L6683.html. Acesso em: 15 mar. 2018.

. Supremo Tribunal Federal. Recurso Extraordinário 466343. Tribunal Pleno. Rel. Min. Cezar Peluso. Data de Julgamento: 03/12/2008. Data de Publicação: 05/06/2009. Disponível em: <http://redir.stf.jus.br/paginadorpub/paginador.jsp?docTP=AC\&docID=595444>. Acesso em: 17 mar. 2018.

. Supremo Tribunal Federal. Habeas Corpus 133992. Primeira Turma. Rel. Min. Edson Fachin. Data de Julgamento: 11/10/2016. Data de Publicação: 22/03/2018. Disponível em: 
<http://www.stf.jus.br/portal/jurisprudencia/visualizarEmenta.asp?s1=000320181\&base=ba seAcordaos>. Acesso em: 31 mar. 2018.

Supremo Tribunal Federal. Habeas Corpus 141949/DF. Segunda Turma. Rel. Min. Gilmar Mendes. Data de Julgamento: 13/03/2018. Data de Publicação: 02/12/2016. Disponível em: $<$ http://www.stf.jus.br/portal/processo/verProcessoAndamento.asp? numero=141949\&class e=HC\&origem=AP\&recurso=0\&tipoJulgamento=M>. Acesso em: 19 mar. 2018.

Superior Tribunal de Justiça. Habeas Corpus 344.989/RJ. Quinta Turma. Rel. Min. Reynaldo Soares da Fonseca. Data de Julgamento: 19/04/2016. Data de Publicação: 28/04/2016. Disponível em: < http://www.stj.jus.br/SCON/jurisprudencia/toc.jsp?i=1\&b=ACOR\&livre=((\%27HC\%27.clas.+e $+@$ num=\%27344989\%27)+ou+(\%27HC\%27+adj+\%27344989\%27.suce.))\&thesaurus=JURIDIC O>. Acesso em: 17 mar. 2018.

Superior Tribunal de Justiça. Habeas Corpus 345.069/SP. Quinta Turma. Rel. Min. Reynaldo Soares da Fonseca. Data de Julgamento: 17/03/2016. Data de Publicação: 30/03/2016. Disponível em: < http://www.stj.jus.br/SCON/jurisprudencia/doc.jsp?processo $=345069 \& b=A C O R \& p=t r u e \& t=J$ URIDICO\&I=10\&i=1>. Acesso em: 17 mar. 2018.

. Superior Tribunal de Justiça. Habeas Corpus no 379.269/MS. Terceira Seção. Rel. Min. Reynaldo Soares da Fonseca. Data de Julgamento: 24/05/2017. Data de Publicação: 30/06/2017. Disponível em: < http://www.stj.jus.br/SCON/jurisprudencia/doc.jsp?processo=379269\&b=ACOR\&p=true \&t=J URIDICO\&I=10\&i=1 >. Acesso em: 31 mar. 2018.

Superior Tribunal de Justiça. Agravo Regimental em Habeas Corpus 353.887/SP. Sexta Turma. Rel. Min. Sebastião Reis Júnior. Data de Julgamento: 19/05/2016. Data de Publicação: 07/06/2016. Disponível em: < http://www.stj.jus.br/SCON/jurisprudencia/doc.jsp?processo $=353887 \& b=A C O R \& p=t r u e \& t=J$ URIDICO\&I=10\&i=1>. Acesso em: 17 mar. 2018.

Superior Tribunal de Justiça. Recurso Especial no 1.640.084/SP. Quinta Turma. Rel. Min. Ribeiro Dantas. Data de Julgamento: 15/12/2016. Data de Publicação: 01/02/2017. Disponível em: <https://ww2.stj.jus.br/processo/revista/documento/mediado/?componente=ITA\&sequenci 

BRASIL: A (IN)APLICABILIDADE DA TEORIA DO DUPLO CONTROLE

al $=1564541 \&$ num_registro $=201600321060 \&$ data $=20170201 \&$ formato=PDF $>$. Acesso em: 31 mar. 2018.

. Superior Tribunal de Justiça. Recurso Ordinário no Habeas Corpus 76.906/SP. Sexta Turma. Rel. Min. Maria Thereza de Assis Moura. Data de Julgamento: 10/11/2016. Data de Publicação: 24/11/2016. Disponível em: < http://www.stj.jus.br/SCON/jurisprudencia/doc.jsp?processo=76906\&b=ACOR\&p=true \&t=J URIDICO\&I=10\&i=1>. Acesso em: 17 mar. 2018.

CONVENÇÃO AMERICANA DE DIREITOS hUMANOS. Pacto de São José da Costa Rica. 1969. Disponível em: <http://www.pge.sp.gov.br/centrodeestudos/bibliotecavirtual/instrumentos/sanjose.htm>. Acesso em: 19 mar. 2018.

CORTE INTERAMERICANA DE DIREITOS HUMANOS. Caso Myrna Mack Chang Vs. Guatemala. 25 nov. 2003. Disponível em: <http://www.corteidh.or.cr/docs/casos/articulos/seriec_101_esp.pdf>. Acesso em: 15 mar. 2018.

. Caso Gomes Lund E Outros (“Guerrilha Do Araguaia”) Vs. Brasil. 24 nov. 2010. Disponível em: <http://www.corteidh.or.cr/docs/casos/articulos/seriec_219_por.pdf>. Acesso em: 15 mar. 2018.

CRESWELL, John W. Projeto de pesquisa: métodos qualitativo, quantitativo e misto. trad. Magda Lopes. 3 ed. - Porto Alegre: Artmed, 2010.

D’ ARAUJO, Maria Celina; SOARES, Glaucio Ary Dilton; CASTRO, Celso. Os anos de chumbo: a memória militar sobre a repressão - Rio de Janeiro: Relume-Dumará, 1994.

FERREIRA, J.; GOMES, A. de C. 1964: o golpe que derrubou um presidente, pôs fim ao regime democrático e instituiu a ditadura no BRASI. $1^{\text {a }}$ ed. - Rio de Janeiro: Civilização Brasileira, 2014.

FIGUEIREDO, Marcelo. O Controle de Constitucionalidade e de Convencionalidade no Brasil. São Paulo: Malheiros, 2016.

FLORES, Joaquin Herrera. Direitos Humanos, Interculturalidade e Racionalidade de Resistência. Seqüência: Estudos Jurídicos e Políticos, Florianópolis. jan. 2002. Disponível em: 
<https://periodicos.ufsc.br/index.php/sequencia/article/view/15330/13921>. Acesso em: 15 mar. 2018. p. 9-30

GUERRA, Sidney. Direito Internacional dos direitos humanos. 2 ed. - São Paulo: Saraiva, 2015.

HENRIQUES, Antônio; MEDEIROS, João Bosco. Metodologia científica na pesquisa jurídica. - 9 ed. - São Paulo: Atlas, 2017.

LAFER, Celso. Em torno dos Méritos da Comissão Nacional da Verdade. In: Direito: Teoria e Experiência. Estudos em Homenagem a Eros Roberto Grau. Tomo II. - São Paulo: Malheiros, 2013. p. 866-873

A reconstrução dos Direitos Humanos: um diálogo com o pensamento de Hannah Arendt. - São Paulo: Companhia das Letras, 1988.

LOPES JR., Aury. Fundamentos do processo penal: introdução crítica. 3 ed. - São Paulo: Saraiva, 2017ạ.

. Prisões Cautelares. - 5 ed. rev. atual. e ampl. - São Paulo: Saraiva, 2017.

MARTÍNEZ, Alejandro Rosillo, et al. Teoria Crítica dos Direitos Humanos no século XXI. - Porto Alegre: EdiPUCRS, 2008.

MARCONI, Marina de Andrade; LAKATOS, Eva Maria. Metodologia do trabalho científico. 7 ed. rev. e ampl. - São Paulo: Atlas, 2011.

MAZZUOLI, Valerio de Oliveira. Teoria geral do controle de convencionalidade no direito brasileiro. Revista de Informação Legis/ativa. Brasília a. 46 n. 181 jan./mar. 2009.

MELO, Juliane Andréa de Mendes Hey; BONATO, Ariadne da Silveira. Cláusula de Abertura dos Direitos Fundamentais e Status Hierárquico dos Tratados Internacionais e Direitos Humanos. Revista direitos humanos e democracia. Unijuí. a. 5. n. 9. jan./jun. 2017. p. 274-305. Disponível em: <https://www.revistas.unijui.edu.br/index.php/direitoshumanosedemocracia>. Acesso em: 16 mar. 2018.

MEZZAROBA, Orides; MONTEIRO, Cláudia Servilha. Manual de Metodologia da Pesquisa no Direito. 5a ed. - São Paulo: Saraiva, 2009. 
ORDEM OS ADVOGADOS DO BRASIL (OAB). Os Direitos Humanos desafiando o século XXI. Brasília: Comissão Nacional de Direitos Humanos, 2009. Disponível em: < http://cedh.ro.gov.br/wp-content/uploads/2015/10/Os-Direitos-Humanos-Desafiando-oS\%C3\%A9culo-XXI.pdf>. Acesso em: 01 abr. 2018.

PAGLIARINI, Alexandre Coutinho. Teoria Geral e Crítica do Direito Constitucional e Internacional dos Direitos Humanos. In: PAGLIARINI, A. C.; DIMOULIS, D. Direito Constitucional e Internacional dos Direitos Humanos. - Belo Horizonte: Fórum, 2012. P. 25-47.

PAIVA, Caio Cezar de Figueiredo Paiva; HEEMAN, Thimotie Aragon. Jurisprudência internacional de direitos humanos. - Manaus: Dizer o Direito, 2015.

PARTIDO COMUNISTA DO BRASIL. Guerra popular: caminho da luta armada no Brasil [1969]. São Paulo: Fundação Maurício Grabois, 2010.

PEIXOTO, Rodrigo Corrêa Diniz. Memória social da Guerrilha do Araguaia e da guerra que veio depois. Bol. Mus. Para. Emílio Goeldi. Cienc. Hum., Belém, v. 6, n. 3, p. 479-499, set.dez. 2011.

PIOVESAN, Flávia. Direitos Humanos e o Direito Constitucional Internacional. 16 ed. rev. ampl. e atual. - São Paulo: Saraiva, 2016.

. Direitos Humanos e Justiça Internacional: um estudo comparativo dos sistemas regionais europeu, interamericano e africano. 7a ed. rev. ampl. e atual. - São Paulo: Saraiva, 2017.

RAMOS, André de Carvalho. Curso de Direitos Humanos. 3 ed. rev., ampl. e atual. - São Paulo: Saraiva, 2016

REZEK, José Francisco. Direito internacional público. 16 ed. rev., ampl. e atual - São Paulo: Saraiva, 2016.

RUBIO, David Sánchez. Derechos humanos, no colonialidad y otras luchas por la dignidad: una mirada parcial y situada. Campo Jurídico. vol. 3. n. 1. p. 181-213. mai. 2015. Disponível em: < http://www.fasb.edu.br/revista/index.php/campojuridico/article/view/82/62>. Acesso em: 26 nov. 2017. 
SANTOS, Boaventura de Sousa Santos. Direitos humanos, democracia e desenvolvimento. 1a ed. - São Paulo: Cortez, 2013.

SILVA, Guilherme Amorim Campos da. A internacionalização dos direitos humanos na fundação de um novo direito constitucional material. In: PAGLIARINI, A. C.; DIMOULIS, D. Direito Constitucional e Internacional dos Direitos Humanos. - Belo Horizonte: Fórum, 2012. P. 73-92.

SILVEIRA, Rodrigo Dias; SCHNEISKI, Christiane. Historicidade e Direitos Humanos. In: BEZERRA; FRANCO (Coord.). Direitos humanos e efetividade: fundamentação e processos participativos - Florianópolis: CONPEDI, 2017. Disponível em: < https://www.conpedi.org.br/publicacoes/27ixgmd9/9h4q89rm/KyZdX1xigpNIPQ38.pdf >. Acesso em: 31 mar. 2018.

TELES, Janaína de Almeida. As disputas pela interpretação da Lei de Anistia de 1979. Ideias. Campinas (SP), v. 1., n..1. p. 71-93. 2010. Disponível em: $<$ https://periodicos.sbu.unicamp.br/ojs/index.php/ideias/article/view/8649306>. Acesso em: 24 dez. 2017.

VARELLA, Marcelo D. Direito Internacional Público. 6ạ ed. - São Paulo: Saraiva, 2016. 